vision is further inquired into by inserting the vulcanite diaphragms in front of the coloured discs. The ground-glass and smoke-glass discs are for the purpose of delineating " misty" and "foggy" atmospheric conditions.

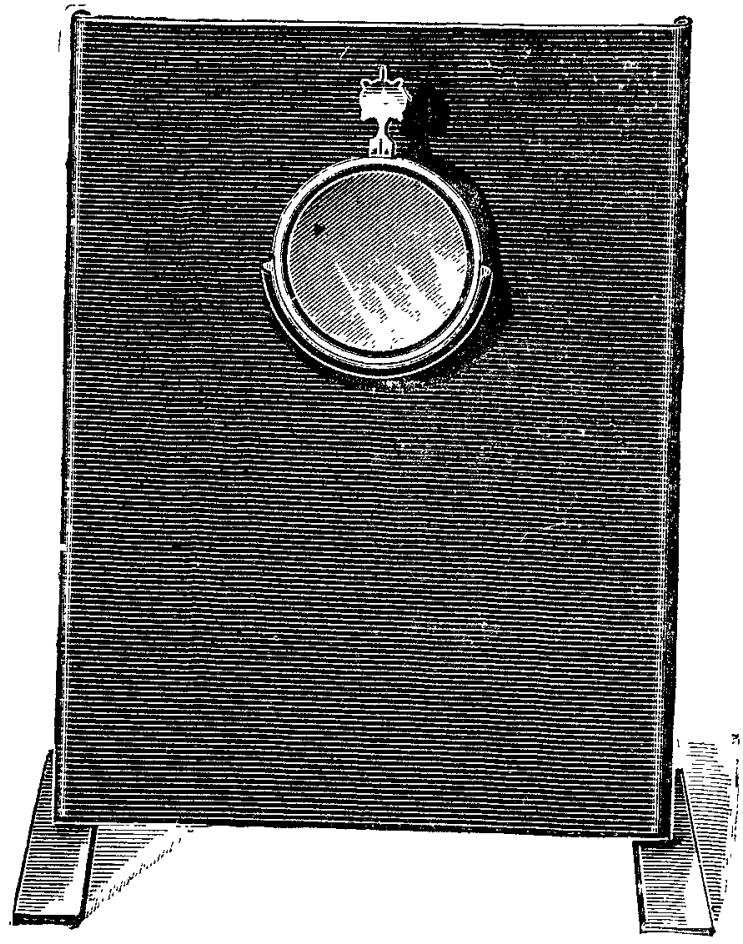

The appliance is supplied in a neat mahogany box and can be obtained from the manufacturer, Mr. F. Davidson, 140, Great Portland-street, London, W., to whom I am much indebted for the care with which he has carried out the design. The cost is very moderate.

Percy Dunn, F.R.C.S. Eng.,

Ophthalmic Surgeon to the West London Hospital ; Lecturer on Ophthalmology at the West London Post-Graduate College. Wimpole-street, $\mathrm{W}$.

\section{A NEW SANATORIUM CHAIR.}

THE accompanying illustration shows a "sanatorium chair" which I have designed and modified after that as used at Belitz, Berlin. During my visit last year to some of the oldest and newest, both public and private, sanatoriums in Germany, the Black Forest, and Switzerland, the one thing I looked out for was a "chaise longue" which might be adapted to any patient. There are here at Bowdon 50 chairs in continual use; these are of cane, firmly made, strengthened by iron supports, but these are unsatisfactory from many points of view. The seats or horizontal portions of chairs are all of the same length and curve, so that tall as well as short patients find them uncomfortable and inconvenient. Mattresses are not being used here, their place

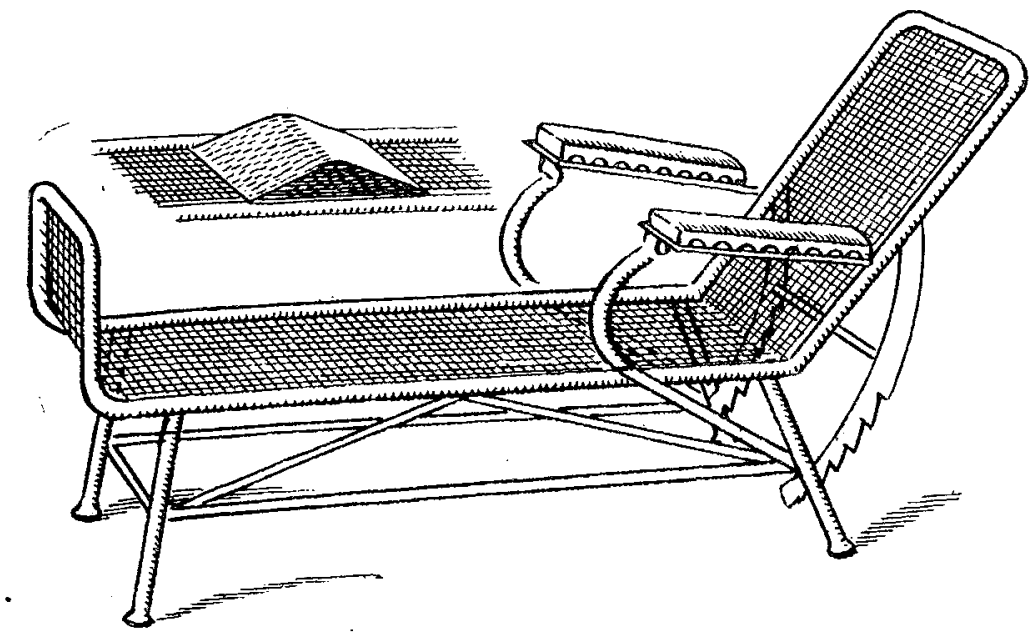

being taken by a plentiful supply of rugs. Those who have control of a sanatorium for consumptives know how costly these chairs may be, as they are being continually repaired, the seats and back supports "sag," give way, and the cane unravels; some are temporarily mended or patched with thick twine, pieces of canvas, or carpet so that they look anything but neat and clean. In the sanatoriums which I visited mattresses and pillows for the chairs were used, most had cane chairs, the exceptions being in the new sanatoriums at Davos (German), Harlaching (Munich), Belzig, and Belitz (Berlin) where iron chairs were employed. The medical directors of the various sanatoriums told me that they found the cane chairs did not give satisfaction owing to constant repairs, renewal, and short "life-history." The points aimed at in my design are neatness, simplicity, cleanliness, durability, and adaptability to suit a patient of any height. The framework is of iron, fitted with a wire mattress (the back and seat portions being in one piece); the arms are covered with leather, the back support being adjustable to any angle. I suggest that no hair or "flock" mattress should be used but that instead thick felt material similar to that as used for stage purposes by acrobats and otbers. Such a "mattress" would be clean, easily rolled up and carried indoors at night, and, above all, sterilisable; on top of this would be placed the wedge-shaped pillow or knee-support depicted in the illustration; this may also be of wire or cane and should be of the same (inside) width as the frame of the chair, easily slid along the mattress under the knees of the patient, and in this way making the chair adaptable to persons of any height. The chair may be had of Mr. Edgar Samuel, Port Talbot, South Wales.

Manchester Sanatorium, Bowdon, Cheshire. D. LLOVD SмIтH.

\section{A MEDICAL BAG.}

I HAVE lately had made for me a bag which I think should prove useful to a large number of medical men. It is of an ordinary "kit-bag" pattern, measuring $16 \times 8 \times 8$ inches. It contains two pockets and the usual arrangement for bottles, loops for a case of catheters, and a steriliser measuring $14 \times 3 \frac{1}{2} \times 2 \frac{1}{2}$ inches inside, which latter will thus take a pair of midwifery forceps or the necessary instruments for most operations, including silver catheters. The lid can be used as a tray during operations and supplies a receptacle never obtainable in private houses, whereas bowls and other necessaries of this description are always at hand. It has been made by Messrs. Bailey of 38, Oxford-street, London, W., who have also put up for me some packets of sterilised gauze already cut up which can be either used as swabs or dressings. Each packet contains a dozen pieces and its contents can be turned out into a bowl of lotion without any direct handling. One has ready at once with these dressings and steriliser all the means for conducting an aseptic operation in a convenient and portable form. Towels which have been boiled can almost always be produced whilst the bandages and wool can be easily kept sufficiently clean. As I have had considerable difficulty in getting what I wanted and as it seems to me of such general utility I thought it might be of some service to indicate where such equipment can be obtained. Convenient methods of sterilising midwifery forceps are seldom, if ever, forthcoming and the stock pattern sterilisers are either too small or too cumbersome, whilst already cut up and sterile dressings obviate the expenditure of a large amount of time and trouble. The bag has sufficient capacity to contain the steriliser and all the instruments and dressings most usually needed, whilst the whole outfit is just as portable as the ordinary general practitioner's bag and, in fact, also serves this purpose. ALEX. R. TwEEDIE, F.R.C.S. Eng.

Market Harborough.

SocIETy fOR RELIEF of WIDOWS and ORPHANS OF MEDICAL MEN.-A quarterly court of the directors of this society was held on April 13th at 11, Chandosstreet, Mr. Christopher Heath, the President, being in the chair. One new member was elected and the deaths of six members were reported. Two widows had become ineligible for further grants. Fresh applications for grants were read from four widows and assistance was given to three, the fourth not being eligible under the by-laws. 54 widows, 14 children, and four orphans on the Copeland Fund applied for a renewal of their grants and $\$ 1319$ were voted for distribution at the next court. A legacy of $£ 1000$ from the late Mrs. Du Pasquier was announced. The following gentlemen were nominated for election at the annual general meeting to fill the vacancies in the court of directors: Mr. K. C. G. Snell, Mr. W. T. N. Bell, Dr. C. Godson, Mr. E. H. May, Dr. W. C. James, Mr. A. W. Green, and Dr. S. West. The expenses of the quarter were $£ 5738.6 d$. It was decided to hold the annual general meeting at 5 P.M. on Wednesday, May 18th. 